\title{
TEACHING SUBJECTS AND PARTICIPATION RATES IN PHYSICAL EDUCATION COURSES AMONG CHILDREN AGED 10 TO 12 YEARS
}

\author{
Konstantinos D. Tambalis ${ }^{1 \mathrm{i}}$, \\ Giannis Arnaoutis ${ }^{1}$, \\ Labros S. Sidossis ${ }^{2}$ \\ ${ }^{1}$ Department of Nutrition and Dietetics, \\ School of Health Science \& Education, \\ Harokopio University, \\ Athens, Greece \\ ${ }^{2}$ Department of Kinesiology and Health, \\ Rutgers University, \\ New Brunswick, NJ 08901, USA
}

\begin{abstract}
:
Physical activity (PA) is a parameter of children's life that is straight connected to the benefits of their life (protection against obesity, better psychological profile, and predisposition for increased levels of PA as adult etc.). The purpose of the present study was to evaluate parameters of PA during Physical Education (PE) classes and to explore the subjects that the children participate in the PE course. PA, PE, and sedentary behaviors were assessed by a self-administrated PA checklist, proper for children. Body mass index (BMI) was calculated from measured body weight and height. A representative sample of Greek boys and girls aged 10 to 12 years $(\mathrm{N}=3195)$ participated in the study. Results showed that boys had higher levels of total and vigorous-intensity PA (VPA), than girls (all p-values<0.05), while girls presented higher light-to-moderate intensity PA as compared to boys. In those days that students participated in PE classes, total PA and VPA were higher in comparison with days didn't, in both sexes $(\mathrm{p}<0.001)$, while, a greater proportion of children met the current recommendations for PA $(86.1 \%$ vs. $69.1 \%$ for boys and $68.4 \%$ vs. $53.5 \%$ for girls). During PE classes, boys participated in a greater proportion than girls in basketball and soccer (all p-values<0.05), while, more girls in comparison to boys participated in volleyball, dance, and jump-rope (all pvalues $<0.05)$. Stratified data analysis by BMI category among children who participated in PE classes did not reveal significant differences in time participated in PE components among categories, except for games (e.g. chase, tag) among boys. In conclusion, boys have higher levels of total PA than girls, while, it seems that school and PE classes play a significant role in students' levels of PA which could grow up further with interventions as the increase of hours in PE lessons.
\end{abstract}

'Correspondence: email dp425603@hua.gr 
Keywords: children, physical activity, school, physical education

\section{Introduction and Literature Review}

Physical activity (PA) is a parameter of children's life associated with health benefits such as avoiding excessive weight gain, lower blood pressure, better psychological profile, predisposition to increased PA as adults, etc. (Blair \& Brodney, 1999). An unhealthy lifestyle in childhood easily leads to a similar lifestyle in adulthood, while a physically active child is more likely to continue to be active in adulthood, gaining significant health benefits (Fogelholm, 2008). Studies in school children have shown that the main risk factors for the development of cardiovascular disease (HDL-C, HDL-C/TC, systolic pressure), are directly related to the levels of PA (Flouris, Bouziotas, Christodoulos, \& Koutedakis, 2008), while generalized prognosis models suggest that changes over time in obesity are significantly associated with PA (Koutedakis, Bouziotas, Flouris, \& Nelson, 2005). Moderate to high-intensity PA may have a better effect on maintaining and promoting health than low-intensity PA (Brown et al., 2004). The World Health Organization recommendations for PA state that children should engage in moderate to high-intensity PA for at least 60 minutes a day to achieve optimal health benefits (World Health Organization, 2016). Moreover, several studies in children have shown a tendency to move away from the active transition to school (by walking or cycling), while, in addition, it appears that a significant number of children do not meet current PA recommendations, results that are more visible in girls (Lee, Orenstein, \& Richardson 2008; Tudor-Locke, Ainsworth, \& Popkin, 2001).

Physical Education (PE) is an integral part of the school program characterized by a planned, sequential curriculum and is recommended internationally as essential as it provides cognitive content and instruction designed to develop knowledge, motor skills, and behaviors to increase PA and organized exercise (US Department of Health and Human Services, 2020). Regular participation in PA is a national learning focus for PE, a focus intended to make possible the establishment of habitual engagement in PA. Studies among children aimed to quantify the benefits of PA and PE during the school day reported that among the benefits included higher levels of physical fitness, reduced body fat, and decreased risk for cardiovascular disease (Dwyer, Coonan, Worsley, Leitch, 1979; Dwyer, Coonan, Leitch, Hetzel, \& Baghurst, 1983). A study exploring the effects of daily PE during elementary school on PA during adulthood revealed that PE was associated with PA in later life for females but not males (Trudeau, Laurencelle, Tremblay, Rajic, \& Shephard, 1999). Also, longitudinal studies propose that PE experiences may be related to adult engagement in PA (Glenmark, 1994; Telama, Yang, Laakso \& Viikari 1997).

Thus, the purposes of the current study were to incorporate parameters of PA during Physical Education (PE) classes and to explore the subjects that the children participate in the PE course in a representative sample of Greek students aged 10 to 12 years, by gender and body mass index status. 


\section{Material and Methods}

\subsection{Participants and Procedures}

Population data derived from a national, school-based, follow-up health survey. A total of 3,195 children (1,602 from the 5th grade and 1,593 from the 6th grade) participated in the study. Five hundred and eighty-four children (18.2\%) were recruited from rural areas and 2,611 children (81.8\%) were recruited from urban areas (boys 50.2\% and $49.8 \%$ girls). Anthropometric, PA, and sedentary behavior data, and information about age, gender, and area, were collected from children in 70 elementary public and private schools randomly selected from the whole country. To avoid potential seasonal effects on P.A., the assessments were performed between September 10 and June 15 (compulsory operation period for all schools of Primary Education in Greece). The schools were from 28 prefectures of Greece, representing over $85 \%$ of the population. The sampling procedure assured the proportional enrolment of children based on the urban/rural areas student population distribution (i.e., flat, mountainous, and island locations) as well as concerning the attendance or not of the PE course. The distribution between rural and urban areas was based on the Hellenic National Statistics Service criteria (consensus 2011). Areas with less than 5,000 inhabitants and a mean population density of 27 inhabitants per square kilometer were considered rural (Services HS, 2010).

To avoid the possible effect of seasonality on the PA and the teaching subjects of the PE, the study was conducted proportionally equally between September 10 and June 15 (period during which students are required to attend Primary Schools). Also, aiming to investigate the average weekly PA of the participants, the study was implemented on Monday (recording the PA of Sunday) and from Tuesday-Friday (recording the PA of Monday to Thursday). The days of the survey were distributed in such a way that on Monday 2/7 of the measurements were performed (holidays) and the other 4 days (Tuesday-Thursday) the remaining 5/7 (school days), respectively. With this separation, an attempt was made to ensure the greater representativeness of the average daily valuation of the weekly PA and PE lessons. The sample number was determined with a sampling rate and statistical power of $85 \%(\alpha=5 \%)$.

\subsection{Self-Administrated Physical Activity Checklist}

The Self-Administered Physical Activity Checklist (SAPAC) used is a translated and slightly modified version of the original questionnaire, which includes the most common activities in the Greek data, suitable for epidemiological studies assessing PA in children (Sallis et al., 1996). In particular, baseball/softball and American football were removed from the standard questionnaire because they are not at all common among Greek students, and handball was added, which is included in the PE curriculum and martial arts (karate, judo, tae-kwon-do, kick-boxing, etc.) as a fairly widespread form of exercise among the children of our country. The SAPAC is a one-day recall questionnaire, it records information of the previous day, closed type, simple, clearly worded, and applied to the whole class at the same time. It includes a list of 21 activities, while there is the 
possibility of recording additional activities that are not mentioned in it. The children record the time (in minutes) for each of the activities listed in the previous day if it lasted at least 5 minutes. The day is divided into three parts: before, during, and after school. In addition, for each reported PA, the children record a personal assessment of its intensity, i.e. they state whether it caused them to pant or get tired: not at all, more or less. Therefore, the questionnaire assesses both organized exercise (school sports, extracurricular sports) and leisure time (walking, free play, etc.) and records their main factors (type, intensity, duration, total volume). Apart from these, other activities-habits of the children are reflected, such as watching TV, playing TV or computer games, and learning foreign languages so that it is possible to assess the overall picture and the leisure activities of the children. In addition, it is foreseen during the planning of the research to record if some children participated in the PE course the day before. Students completed the questionnaire in the classroom under the guidance and supervision of trained PE teachers. Before completing the questionnaire, a short presentation preceded it, for students to better understand the requirements and possibly improve the accuracy of the reported data. The children were asked to read the completed questionnaire twice, while the researcher, when needed, provided the necessary assistance during its completion. A survey of a Greek student population aged 10-12 years showed that the questionnaire has moderate to good reliability $(\mathrm{r}>0.85, \mathrm{p}<0.001)$ and validity $(\mathrm{r}=0.31$ to 0.37, p<0.001) (Gioxari, Kavouras, Tambalis, Maraki, Kollia, \& Sidossis, 2013).

\subsection{Anthropometric Measurements}

Body height was measured by the weight distributed on both legs, the back resting on the wall, and the head in a straight line with a portable height meter (Leicester Height Measurement, TANITA). Bodyweight was measured without shoes and with light clothing with electronic scales (Body Fat Monitor Scale, TANITA BF-522W), in kilograms to the nearest $0.1 \mathrm{~kg}$ (e.g. $38.3 \mathrm{~kg}$ ). It has been imprinted in meters with two decimal places at the nearest $0.5 \mathrm{~cm}$. In particular, for the electronic scale, quality control was performed quarterly regarding the accuracy of its measurements. The Body Mass Index (BMI) was calculated based on the equation: weight $(\mathrm{kg})$ by height $(\mathrm{m})$ squared $(\mathrm{kg} / \mathrm{m} 2)$. BMI cutoff points were used by age and gender category (according to IOTF) for underweight, normal weight, overweight, and obese, as the most proper for epidemiologic studies (Cole, Flegal, Nicholls, \& Jackson, 2007).

\subsection{Data Processing and Statistical Analysis}

Initially, all components of SAPAC were encoded in Metabolic Equivalent (MET) values using the original categorization (Ainsworth et al., 2000). PA components were rated as low to moderate intensity (LMPA) if their value was $<5.9$ MET, moderate to high intensity (MVPA) if their value was $\geq 2.9 \mathrm{MET}$, while high intensity (VPA) if their value was $\geq 5.9$ MET. The minutes of each recorded PA were multiplied by the corresponding MET value to calculate their MET score. Participants were classified as "active commuters" if they walked or biked to and from school and "passive commuters" if they were driven to and 
from school. Additionally, participants were stratified depending on meeting recommended activity level or not. Specifically, children who participated in MVPA at least 60 minutes per day were considered they be meeting the recommendations for PA level (Bull et al, 2020).

Descriptive characteristics are presented as mean \pm standard deviation (Mean \pm $\mathrm{SD})$ or as percentages (\%). Differences of PA sub-components between genders were assessed using independent samples t-test. Comparisons of the categorical variables (i.e., gender, and BMI categories) were performed using Pearson's chi-square test. Comparisons between differences of mean values of normally distributed variables between BMI categories were tested using the analysis of variance (ANOVA). To evaluate the differences between two specific BMI categories we applied post hoc analysis using the Bonferroni correction rule to adjust for the inflation of Type I error. Normality of residuals, homoscedasticity, and serial dependency was graphically assessed through QQ plots. All analyses were performed using the SPSS version 18.0 software for Windows (SPSS Inc., Chicago, Ill, USA). Statistical significance level from two-sided hypotheses was accepted at the $5 \%$ level $(\mathrm{p} \leq 0.05)$.

\section{Results}

Mean values for descriptive participants' characteristics were tabulated by gender (Table 1). Boys reported higher levels of total PA, VPA, and total MET's score than girls (all pvalues $<0.05$ ), while a greater proportion of them met PA guideline recommendations, as compared to girls (Table 1). On contrary, girls reported longer time on LMPA (pvalue $<0.001$ ) than boys. The higher LMPA of girls was more free games (e.g. chase, tag, hopscotch), outdoor play (e.g. climbing trees, hide and seek), and outdoor and indoor chores. When we compared the children by PE classes (Table 2), we found that children who participated in PE class had significantly higher total PA $(146 \pm 56 \mathrm{~min} / \mathrm{d}$ for boys and $138 \pm 55 \mathrm{~min} / \mathrm{d}$ for girls) and VPA $(83 \pm 45 \mathrm{~min} / \mathrm{d}$ for boys and $43 \pm 40 \mathrm{~min} / \mathrm{d}$ for girls) compared to children did not participate (all p-values $<0.05$ ), while statistically significant more boys and girls participated in PE classes met the recommendations for PA than those did not participate ( $86.1 \%$ vs. $69.1 \%$ for boys and $68.4 \%$ vs. $53.5 \%$ for girls).

Table 1: Descriptive characteristics and main physical activity variables of the participants

\begin{tabular}{|l|c|c|}
\hline & $\begin{array}{c}\text { Boys } \\
(\mathbf{n = 1 6 3 5 )}\end{array}$ & $\begin{array}{c}\text { Girls } \\
(\mathbf{n = 1 5 6 0 )}\end{array}$ \\
\hline Age $(\mathrm{y})$ & $11.0(1.0)$ & $11.0(1.0)$ \\
\hline Weight $(\mathrm{kg})$ & $47.9(11.5)$ & $48.0(10.7)$ \\
\hline Height $(\mathrm{cm})$ & $150.1(8.5)$ & $150.6(8.1)$ \\
\hline BMI $\left(\mathrm{kg} / \mathrm{m}^{2}\right)$ & $21.1(3.8)$ & $21.1(3.6)$ \\
\hline Overweight $(\%)$ & 28.0 & 27.7 \\
\hline Obese $(\%)$ & 11.5 & 10.6 \\
\hline Waist circumference $(\mathrm{cm})$ & $73.5(11.2)$ & $71.9(11.1)$ \\
\hline Total PA $(\mathrm{min} / \mathrm{d})$ & $127(55)$ & $116(56)^{*}$ \\
\hline
\end{tabular}


EDUCATION COURSES AMONG CHILDREN AGED 10 TO 12 YEARS

\begin{tabular}{|l|c|c|}
\hline \hline Light to moderate PA (min/d) & $64(42)$ & $89(52)^{*}$ \\
\hline Vigorous PA (min/d) & $63(43)$ & $27(32)^{*}$ \\
\hline Total MET's score (MET) & $690(328)$ & $550(284)^{*}$ \\
\hline Sedentary behaviours (min/d) & $151(86)$ & $139(83)$ \\
\hline Physical Education classes (\%) & 22.4 & 21.9 \\
\hline Active transportation to school (\%) & 46.6 & 48.3 \\
\hline Meeting recommended PA§ level(\%) & 72.6 & $57.1^{*}$ \\
\hline $\begin{array}{l}\text { Values are mean (SD) or frequencies (\%); BMI, body mass index; PA, physical activity; MET, metabolic } \\
\text { equivalent. sRecommended activity level } \geq 60 \text { min of moderate to vigorous PA daily. } \\
\text { *P<0.05 for differences between boys and girls. }\end{array}$ \\
\hline
\end{tabular}

Table 2: Self-reported physical activity variables by Physical Education participation status

\begin{tabular}{|l|c|c|c|c|}
\hline & \multicolumn{2}{|c|}{ Yes } & \multicolumn{2}{c|}{ No } \\
\hline & Boys & Girls & Boys & Girls \\
\hline & Mean (SD) & Mean (SD) & Mean (SD) & Mean (SD) \\
\hline Total PA (min/d) & $146(56)$ & $138(55)$ & $122(58)^{*}$ & $110(55)^{*}$ \\
\hline Light to moderate PA (min/d) & $63(44)$ & $95(52)$ & $65(44)$ & $87(53)^{*}$ \\
\hline Vigorous PA (min/d) & $83(45)$ & $43(40)$ & $57(43)^{*}$ & $23(29)^{*}$ \\
\hline Total MET's score (MET) & $815(343)$ & $667(305)$ & $652(337)^{*}$ & $523(282)$ \\
\hline Sedentary behaviors (min/d) & $137(84)$ & $139(86)$ & $159(89)^{*}$ & $136(85)$ \\
\hline Active transportation to school (\%) & 51.3 & 50.9 & 48.7 & 49.1 \\
\hline Meeting recommended PA§ level (\%) & 86.1 & 68.4 & $69.1^{*}$ & $53.5^{*}$ \\
\hline $\begin{array}{l}\text { Values are mean (SD) or frequencies (\%); PA, physical activity; } \\
\text { *P<0.05 for differences between Physical Education participation status from the same gender. }\end{array}$ \\
\hline
\end{tabular}

Table 3 presents the physical activities in which the students reported that they participated during the PE lesson. Higher percentages of boys participated in basketball and football compared to girls (all p-values<0.05), while greater proportions of girls participated in volleyball, dancing, and jump-rope than boys (all p-values $<0.05$ ). Finally, except for the participation time in the jump-rope where girls declared significantly higher time [12.3 (3.5) vs. 9.6 (4.7), p<0.05] than boys, no significant differences were recorded between genders in any other PA. Stratified data analysis by BMI category among boys and girls who participated in PE classes (Table 4) revealed significant differences among normal-weight and overweight and obese only for games (e.g. chase, tag) in boys.

\section{Discussion}

PA levels have emerged as factors that affect children's health (Janssen, \& Leblanc, 2010). The purpose of this study was to record the levels of PA during PE courses and to investigate parameters of PE such as students' participation rates and curriculum components. The population data is based on a two-year survey of a representative sample of 3,195 students from all geographical regions of the country. The self-reported PA questionnaire used in the present study has been designed for children and in 
comparison, with other similar PA, questionnaires are presented as one of the most reliable (Sirard, \& Pate, 2001).

Table 3: Participation rates, time, and Metabolic equivalent of Physical Education curriculum components by gender

\begin{tabular}{|l|c|c|c|c|c|c|}
\hline & \multicolumn{3}{|c|}{ Boys } & \multicolumn{3}{c|}{ Girls } \\
\hline & $\begin{array}{c}\text { Participation } \\
\mathbf{( \% )}\end{array}$ & $\begin{array}{c}\text { Min/d } \\
\text { (Mean } \pm \text { SD) }\end{array}$ & $\begin{array}{c}\text { MET/d } \\
\text { Mean } \pm \text { SD) }\end{array}$ & $\begin{array}{c}\text { Participation } \\
\text { (\%) }\end{array}$ & $\begin{array}{c}\text { Min/d } \\
\text { (Mean } \pm \text { SD) }\end{array}$ & $\begin{array}{c}\text { MET/d } \\
\text { (Mean } \pm \text { SD) }\end{array}$ \\
\hline $\begin{array}{l}\text { Exercises (e.g. } \\
\text { jumping jacks) }\end{array}$ & 7.8 & $5.9(1.9)$ & $3.0(10.7)$ & 6.6 & $6.3(2.3)$ & $2.8(10.1)$ \\
\hline Basketball & 12.5 & $32.4(6.9)$ & $25.4(57.4)$ & $7.6^{*}$ & $31.6(6.1)$ & $24.5(45.6)$ \\
\hline Soccer & 32.1 & $33.7(12.8)$ & $70.3(85.8)$ & $5.6^{*}$ & $29.6(10.9)^{*}$ & $57.1(68.2)^{*}$ \\
\hline Handball & 3.6 & $27.3(13.5)$ & $25.6(49.8)$ & 4.5 & $27.2(11.6)$ & $24.2(48.8)$ \\
\hline Running/track/field sports & 14.3 & $11.9(12.1)$ & $10.7(34.5)$ & 18.5 & $12.7(11.7)$ & $12.1(37.8)$ \\
\hline Jump-rope & 0.6 & $9.6(4.7)$ & $3.5(7.5)$ & $3.4^{*}$ & $12.2(5.3)^{*}$ & $5.6(11.0)^{*}$ \\
\hline Mixed running and walking & 10.2 & $14.7(8.2)$ & $11.8(32.1)$ & 13.3 & $14.2(8.6)$ & $11.2(39.8)$ \\
\hline Ball-games & 13.1 & $27.1(12.2)$ & $21.8(49.2)$ & 17.0 & $26.9(16.7)$ & $22.2(51.3)$ \\
\hline Volleyball & 2.5 & $33.3(8.7)$ & $9.3(25.5)$ & $12.9^{*}$ & $32.7(9.6)$ & $9.9(32.4)$ \\
\hline Gymnastics & 0.3 & $9.5(3.7)$ & $2.1(2.2)$ & 0.9 & $11.9(4.3)$ & $2.6(4.9)$ \\
\hline Dance & 1.0 & $16.7(10.7)$ & $2.8(9.9)$ & $4.5^{*}$ & $17.6(11.9)$ & $2.9(11.1)$ \\
\hline Walking & 9.5 & $13.3(6.6)$ & $4.2(18.4)$ & 13.0 & $14.2(7.3)$ & $4.4(19.5)$ \\
\hline Racket sports & 0.3 & $2.6(3.7)$ & $1.1(1.9)$ & 0.8 & $3.7(4.1)$ & $1.4(2.2)$ \\
\hline Games (e.g. chase, tag) & 31.6 & $24.8(12.2)$ & $40.9(68.8)$ & 34.1 & $23.5(10.9)$ & $38.7(62.3)$ \\
\hline Other physical activity & 0.9 & $10.0(3.4)$ & $3.3(10.0)$ & 1.2 & $13.5(4.2)$ & $3.9(5.1)$ \\
\hline MET: Metabolic equivalent; ${ }^{*}$ P<0.05 for differences between genders. & & & \\
\hline
\end{tabular}

In the current study, the results showed that boys as compared to girls, had higher levels of total and VPA and longer screen time, while a higher percentage of them met the recommended levels of PA ( $\geq 60$ minutes MVPA each day). Regarding the differences in PA levels between the sexes, our results are in line with several studies which showed that boys had higher levels of total and MVPA as compared to girls (Jones et al., 2009; Kriemler et al., 2008; Purslow, Hill, Saxton, Corder, \& Wardle, 2008). In addition, surveys in our country among Primary School children add that more boys are involved in MVPA than girls (Magkos et al., 2006; Manios, Kafatos, \& Codrington, 1999). Finally, a review study among children from 41 countries (including Greece) showed that girls reported less PA than boys, and also a smaller percentage of girls had reached the recommended PA levels (Haug et al, 2009). Moreover, further analyzes showed that the higher time of LMPA of girls as compared to boys is attributed to the increased time in free games (e.g. hunting, lame), outdoor games (e.g. hidden), and indoor and outdoor work.

The population data in our country (Tambalis et al, 2010) suggest that Greek children are probably the most obese in Europe, while a significant percentage of them do not meet the recommended levels of PA. In addition to the PE course, the school can provide opportunities for PA through breaks, and post-course exercise programs. Because the child spends almost half of the day at school, the state must ensure that children participate at least 30 minutes a day in MVPA during the school day. According 
to the results of the present research, this time is almost covered if the PE class is included in the school curriculum daily and therefore is unreservedly proposed.

Then, based on scientific findings that report a global decline in the percentage of children who go to school on foot or bicycle and the potential relation of their mode of transport with the total PA (Davison, Werder, \& Lawson, 2008) emerged the need to investigate the mode of transfer to the school. The results showed that about $50 \%$ of children use an active mode of transport, a finding that is consistent with other researches (Lee et al., 2008; Panter, Jones, van Sluijs, \& Griffin, 2010), while no significant differences were found in rates of active transfer between the sexes.

The mean time of sedentary behaviors (screen time) in the present study was about 151 minutes/day for boys and 139 minutes/day for girls. These findings are consistent with a review of 539 studies in young people under the age of 18, which reported that the average screen viewing time ranged from 1.8 to 2.8 hours (Marshall, Gorely, \& Biddle, 2006). Similarly, the above findings are in line with a study in our country which, although examining younger children, found that their mean screen viewing time exceeded 1.5 hours (Manios, Kourlaba, Kondaki, Grammatikaki, Anastasiadou, \& RomaGiannikou, 2009).

Furthermore, it seems that there are no significant differences in the time of participation in the various sports activities during PE classes between the two sexes, except for jump-rope, a finding that probably means that when children participate in PE classes follow the same program. The higher participation rates of boys in basketball and football and girls in volleyball and dance are probably due to their free choices which are allowed during the PE course in Greek schools.

In addition, an encouraging finding from the present study was that there were no significant differences in the time of participation in the various sports activities of the PE course among the BMI categories of the students. The above finding clearly shows that in the PE course there are no exclusions or restrictions due to the different physical abilities of the students, but instead, a successful effort is made for equal participation of all students.

Risk factors assessed in this study (PA levels, obesity status, sedentary habits) are likely to contribute to the development of cardiovascular disease in adulthood, and prevention of possible diseases is preferable to start in childhood (Hayman et al., 2007). The above conclusions highlight some suggestions, easy to implement as they apply to all children regardless of gender, weight category, or financial status and the low cost concerning the intended benefit to children's health. For example, an active transfer of children to school could provide an increase in PA time by an average of about 16 minutes (which is the average active transfer time to school). Also, the increase of the teaching hours of the PE course daily with a parallel extension of the schedule could cover the required PA recommendations for good health. 
Konstantinos D. Tambalis, Giannis Arnaoutis, Labros S. Sidossis TEACHING SUBJECTS AND PARTICIPATION RATES IN PHYSICAL EDUCATION COURSES AMONG CHILDREN AGED 10 TO 12 YEARS

Table 4: Mean time \pm SD of Physical Education curriculum components by obesity group and gender

\begin{tabular}{|c|c|c|c|}
\hline & Normal-weight & Overweight & Obese \\
\hline \multicolumn{4}{|l|}{ Boys } \\
\hline Exercises (e.g. jumping jacks) (min/d) & $6.0(1.9)$ & $5.9(1.9)$ & $5.8(1.8)$ \\
\hline Basketball (min/d) & $33.4(6.9)$ & $32.4(6.7)$ & $30.8(6.4)$ \\
\hline Soccer $(\mathrm{min} / \mathrm{d})$ & $33.5(12.8)$ & $33.3(12.1)$ & $30.7(11.8)$ \\
\hline Handball (min/d) & $27.4(13.5)$ & $26.5(12.8)$ & $25.5(11.9)$ \\
\hline Running/track and field sports (min/d) & $12.1(11.9)$ & $10.9(12.2)$ & $10.2(11.3)$ \\
\hline Jump-rope $(\mathrm{min} / \mathrm{d})$ & $9.8(4.7)$ & $9.1(4.4)$ & $8.8(4.1)$ \\
\hline Mixed running and walking $(\mathrm{min} / \mathrm{d})$ & $15.0(8.3)$ & $14.3(8.0)$ & $13.7(7.8)$ \\
\hline Ball-games $(\mathrm{min} / \mathrm{d})$ & $28.0(12.3)$ & $26.7(12.0)$ & $27.2(11.2)$ \\
\hline Volleyball (min/d) & $33.9(8.9)$ & $30.9(8.3)$ & $31.8(8.5)$ \\
\hline Gymnastics (min/d) & $9.8(3.8)$ & $9.0(3.5)$ & $8.3(2.7)$ \\
\hline Dance $(\mathrm{min} / \mathrm{d})$ & $18.1(10.9)$ & $16.3(9.7)$ & $16.0(11.7)$ \\
\hline Walking $(\mathrm{min} / \mathrm{d})$ & $14.2(6.7)$ & $13.2(6.0)$ & $13.7(5.9)$ \\
\hline Racket sports (min/d) & $2.7(3.5)$ & $2.6(3.4)$ & $2.2(3.0)$ \\
\hline Games (e.g. chase, tag) $(\mathrm{min} / \mathrm{d})$ & $25.2(12.0)$ & $21.8(12.1)^{*}$ & $20.6(11.4)^{\prime}$ \\
\hline Other physical activity $(\mathrm{min} / \mathrm{d})$ & $10.8(3.4)$ & $11.2(3.1)$ & $11.0(2.6)$ \\
\hline \multicolumn{4}{|l|}{ Girls } \\
\hline Exercises (e.g. jumping jacks(min/d) & $7.0(2.7)$ & $5.8(1.9)$ & $5.8(1.8)$ \\
\hline Basketball $(\mathrm{min} / \mathrm{d})$ & $33.1(4.9)$ & $28.5(3.7)$ & $28.1(7.4)$ \\
\hline Soccer $(\mathrm{min} / \mathrm{d})$ & $31.4(10.8)$ & $28.3(11.1)$ & $27.4(13.8)$ \\
\hline Handball $(\mathrm{min} / \mathrm{d})$ & $27.5(11.5)$ & $26.4(10.8)$ & $26.0(7.9)$ \\
\hline Running/track and field sports (min/d) & $14.1(10.9)$ & $11.9(12.2)$ & $10.9(11.7)$ \\
\hline Jump-rope $(\mathrm{min} / \mathrm{d})$ & $12.8(5.7)$ & $9.6(4.7)$ & $9.8(4.9)$ \\
\hline Mixed running and walking $(\mathrm{min} / \mathrm{d})$ & $14.7(8.3)$ & $13.9(8.6)$ & $13.7(7.8)$ \\
\hline Ball-games (min/d) & $27.0(17.3)$ & $26.2(16.0)$ & $28.8(17.2)$ \\
\hline Volleyball (min/d) & $33.2(9.5)$ & $31.9(10.3)$ & $33.8(9.7)$ \\
\hline Gymnastics (min/d) & $12.2(4.0)$ & $10.9(3.9)$ & $9.8(3.7)$ \\
\hline Dance $(\mathrm{min} / \mathrm{d})$ & $17.9(11.9)$ & $17.6(11.7)$ & $17.6(12.0)$ \\
\hline Walking $(\mathrm{min} / \mathrm{d})$ & $14.0(6.7)$ & $14.2(7.6)$ & $14.7(7.9)$ \\
\hline Racket sports $(\mathrm{min} / \mathrm{d})$ & $3.6(4.0)$ & $3.8(4.4)$ & $3.6(4.1)$ \\
\hline Games (e.g. chase, tag) $(\mathrm{min} / \mathrm{d})$ & $25.2(11.0)$ & $23.3(10.4)$ & $22.6(10.8)$ \\
\hline Other physical activity $(\mathrm{min} / \mathrm{d})$ & $13.8(4.3)$ & $13.2(4.1)$ & $13.1(4.6)$ \\
\hline
\end{tabular}

The results of the present study should be evaluated and interpreted carefully about possible confounding factors (energy intake, sexual maturation, etc.), which have not been evaluated. Self-reported PA questionnaires for children are widespread, mainly for their ease of use and low cost, but they are powerless to produce accurate estimates of the type and duration of PA and may not be able to adequately assess PA at home (Warren, Ekelund, Besson, Mezzani, Geladas, \& Vanhees, 2010). They are also considered unreliable as a method of calculating the energy cost of PA (Warren et al., 2010). Differences in the level of sexual maturity between the sexes can affect the levels of PA during adolescence (Cumming, Standage, Gillison, \& Malina, 2008; Drenowatz, 
Eisenmann, Pfeiffer, Wickel, Gentile, \& Walsh, 2010). In the present study, sexual maturity was not assessed and therefore it was not possible to rule out its possible effect on gender differences between sexes. In addition, the research methodology (observational study) cannot create causal correlations, only hypotheses for further investigation.

\section{Recommendations}

Informing health officials and experts about the levels of PA and sedentary habits of children may help in the development of public health policies, to create in-school or outof-school actions to safeguard the health of children. Specifically, these interventions concern: (a) the increase of the teaching hours of the PE course in all types and classes of schools; (b) the modification of the curricula of PE to place special emphasis on the continuous PA of the students and (c) the creation of the conditions (suitable spaces, security, equipment, etc.), so that students are more physically active during their stay at school.

\section{Conclusion}

In conclusion, the results of the present study show that gender has a net effect on PA levels at least among children aged 10-12 years. Students who participated in PE classes had higher total PA and VPA and a greater proportion met the current recommendations for PA in comparison with students who didn't participate. Also, during PE classes, boys participated in a greater proportion than girls in basketball and soccer, while, more girls in comparison to boys participated in volleyball, dance, and jump-rope. Stratified data analysis by BMI category among children who participated in PE classes did not reveal significant differences in time participated in PE components among categories. Greek school and PE play an important role in the levels of PA of students which could be further developed with interventions such as increasing the hours of PE.

\section{Acknowledgments}

This work was supported by the Graduate Program, Department of Nutrition and Dietetics of Harokopio University, the Hellenic Atherosclerosis Society, and the Hellenic Heart Foundation.

\section{Conflict of Interest Statement}

The authors declare no conflicts of interest.

\section{Authors' contribution}

Konstantinos D. Tambalis designed the study, performed the data collection and analysis, and wrote the paper. Giannis Arnaoutis participated in the design of the study 
and critically reviewed the paper. Labros S. Sidossis was involved in the study design, manuscript writing, and overall supervision of the study.

\section{About the Authors}

Konstantinos D. Tambalis, (MSc, MSc, PhD) is a Teaching and Research Associate at the Department of Nutrition and Dietetics of the Harokopio University in Greece. His research interests are in the areas of Physical Education, epidemiology of exercise and athletic nutrition.

Giannis Arnaoutis, (MSc, PhD) is a Teaching and Research Associate at the Department of Nutrition and Dietetics of the Harokopio University in Greece. His research interests are in the areas of athletic nutrition, exercise physiology and exercise performance.

Labros S. Sidossis (MSc, PhD) is a Professor at the Department of Kinesiology and Health of the Rutgers University of New Jersey (USA). His research interests are in the areas of metabolism, nutrition and exercise performance.

\section{References}

Ainsworth BE, Haskell WL, Whitt MC, Irwin ML, Swartz AM, Strath SJ, O'Brien WL, Bassett Jr DR, Schmitz KH, Emplaincourt PO, Jacobs Jr DR, Leon AS, 2000. "Compendium of physical activities: an update of activity codes and MET intensities. Medicine and Science in Sports and Exercise 32: 498-504.doi: 10.1097/00005768-200009001-00009

Blair SN, Brodney S, 1999. Effects of physical inactivity and obesity on morbidity and mortality: current evidence and research issues. Medicine \& Science in Sports \& Exercise 31: 646-662. doi: 10.1097/00005768-199911001-00025

Brown DW, Brown DR, Heath GW, Balluz L, Giles WH, Ford ES, Mokdad AH, 2004. Associations between physical activity dose and health-related quality of life. Medicine \& Science in Sports \& Exercise 36: 890-896.doi: 10.1249/01.mss.0000126778.77049.76

Bull FC, Al-Ansari SS, Biddle S, Borodulin K, Buman MP, Cardon G, Carty C, Chaput J P, Chastin S, Chou R, Dempsey PC, DiPietro L, Ekelund U, Firth J, Friedenreich CM, Garcia L, Gichu M, Jago R, Katzmarzyk PT, Lambert E, Willumsen JF, 2020. World Health Organization 2020 guidelines on physical activity and sedentary behaviour. British journal of sports medicine 54(24): 1451-1462. doi:10.1136/bjsports-2020-102955

Cole TJ, Flegal KM, Nicholls D, Jackson AA, 2007. Body mass index cut offs to define thinness in children and adolescents: international survey. BMJ (Clinical research ed.), 335(7612), 194. doi:10.1136/bmj.39238.399444.55

Cumming SP, Standage M, Gillison F, Malina RM, 2008. Sex differences in exercise behavior during adolescence: is biological maturation a confounding factor? Journal of Adolescence Health 42: 480-485. doi: 10.1016/j.jadohealth.2007.10.005 
Davison KK, Werder JL, Lawson CT, 2008. Children's active commuting to school: current knowledge and future directions. Preventive Chronic Diseases 5: 100-105.PMCID: PMC2483568

Drenowatz C, Eisenmann JC, Pfeiffer KA, Wickel EE, Gentile D, Walsh D, 2010. Maturityrelated differences in physical activity among 10- to 12-year-old girls. American Journal ofHuman Biology 22: 18-22.doi: 10.1002/ajhb.20905

Dwyer T, Coonan W, Worsley A, Leitch D, 2010. An assessment of the effects of two physical activity programmes on coronary heart disease risk factors in primary school children. Australian and New Zealand Journal of Public Health 3(3): 196202. doi.org/10.1111/j.1753-6405.1979.tb00254.x

Dwyer T, Coonan WE, Leitch DR, Hetzel BS, Baghurst RA, 1983. An investigation of the effects of daily physical activity on the health of primary school students in South Australia. International journal of epidemiology 12(3): 308-313. doi.org/10.1093/ije/12.3.308

Physical activity strategy for the WHO European Region 2016-2025. https://www.euro.who.int/ data/assets/pdf file/0014/311360/Physical-activitystrategy-2016-2025.pdf. Accessed 14 December 2021

Flouris AD, Bouziotas C, Christodoulos AD, Koutedakis Y, 2008. Longitudinal preventive-screening cutoffs for metabolic syndrome in adolescents. International Journal of Obesity 32: 1506-1512. doi: org/10.1038/ijo.2008.142

Fogelholm M, 2008. How physical activity can work? International Journal of Pediatric Obesity 3 (Suppl 1): 10-14. doi: 10.1080/17477160801896481

Gioxari A, Kavouras SA, Tambalis KD, Maraki M, Kollia M, Sidossis LS, 2013. Reliability and criterion validity of the Self-Administered Physical Activity Checklist in Greek children. European Journal of Sports Science 13: 105111.doi:10.1080/17461391.2011.606838

Glenmark B, 1994. Skeletal muscle fiber types, physical performance, physical activity and attitude to physical activity in women and men: A follow-up from age 16-27. Acta Physiologica Scandinavica Supplementum 623: 1-47. PMID: 7942046

Haug E, Rasmussen M, Samdal O, Iannotti R, Kelly C, Borraccino A, et al., 2009. Overweight in school-aged children and its relationship with demographic and lifestyle factors: results from the WHO-Collaborative Health Behaviour in Schoolaged Children (HBSC) study. International Journal of Public Health 54: 167179.doi: $10.1007 / \mathrm{s} 00038-009-5408-6$

Hayman LL, Meininger JC, Daniels SR, McCrindle BW, Helden L, Ross J, Dennison BA, Steinberger J, Williams CL, 2007. Primary prevention of cardiovascular disease in nursing practice: focus on children and youth: a scientific statement from the American Heart Association Committee on Atherosclerosis, Hypertension, and Obesity in Youth of the Council on Cardiovascular Disease in the Young, Council on Cardiovascular Nursing, Council on Epidemiology and Prevention, and Council on Nutrition, Physical Activity, and Metabolism. Circulation 116: 344357.doi: 10.1161/CIRCULATIONAHA.107.184595 
Janssen I, Leblanc AG, 2010. Systematic review of the health benefits of physical activity and fitness in school-aged children and youth. International Journal of Behavioral Nutrition and Physical Activity 7: 40.doi: 10.1186/1479-5868-7-40

Jones AP, Coombes EG, Griffin SJ, van Sluijs EM, 2009. Environmental supportiveness for physical activity in English schoolchildren: a study using Global Positioning Systems. International Journal of Behavioural Nutrition and Physical Activity 6: 42. doi: 10.1186/1479-5868-6-42

Koutedakis Y, Bouziotas C, Flouris A, Nelson P, 2005. Longitudinal modelling of adiposity in periadolescent Greek schoolchildren. Medicine \& Science in Sports \& Exercise 37: 2070-2074. doi: 10.1249/01.mss.0000178099.80388.15

Kriemler S, Manser-Wenger S, Zahner L, Braun-Fahrländer C, Schindler C, Puder JJ, 2008. Reduced cardiorespiratory fitness, low physical activity and an urban environment are independently associated with increased cardiovascular risk in children. Diabetologia 51: 1408-1415.doi: 10.1007/s00125-008-1067-z

Lee MC, Orenstein MR, Richardson MJ, 2008. Systematic review of active commuting to school and childrens physical activity and weight. Journal of Physical Activity \& Health 5(6): 930-949.doi: 10.1123/jpah.5.6.930

Magkos F, Piperkou I, Manios Y, Papoutsakis C, Yiannakouris N, Cimponerio A, 2006. Diet, blood lipid profile and physical activity patterns in primary school children from a semi-rural area of Greece. Journal of Human Nutrition and Dietetics 19: 101-112.doi: 10.1111/j.1365-277X.2006.00675.x

Manios Y, Kafatos A, Codrington C, 1999. Gender differences in physical activity and physical fitness in young children in Crete. Journal of Sports Medicine and Physical Fitness 39: 24-30.PMID: 10230165

Manios Y, Kourlaba G, Kondaki K, Grammatikaki E, Anastasiadou A, Roma-Giannikou E, 2009. Obesity and television watching in preschoolers in Greece: the GENESIS study. Obesity 17: 2047-2053.doi: 10.1038/oby.2009.50

Marshall SJ, Gorely T, Biddle SJ, 2006 A descriptive epidemiology of screen-based media use in youth: a review and critique. Journal of adolescence 29(3): 333-49. doi: 10.1016/j.adolescence.2005.08.016

Panter JR, Jones AP, van Sluijs EM, Griffin SJ, 2010. Attitudes, social support and environmental perceptions as predictors of active commuting behaviour in school children. Journal of Epidemiology and Community Health 64: 41-48.doi: 10.1136/jech.2009.086918

Purslow LR, Hill C, Saxton J, Corder K, Wardle J, 2008. Differences in physical activity and sedentary time in relation to weight in 8-9 year old children. International Journal of Behavioral Nutrition and Physical Activity 5: 67-69.doi: 10.1186/14795868-5-67

Sallis JF, Strikmiller PK, Harsha DW, Feldman HA, Ehlinger S, Stone EJ, Williston J, Woods S, 2006. "Validation of interviewer- and self-administered physical activity checklists for fifth grade students". Medicine and Science in Sports and Exercise 28: 840-851. doi: 10.1097/00005768-199607000-00011 
Services HS. Demographic, economic and household data (Volume V), 2001. Available from: http://www.statistics.gr/portal/page/portal/ESYE. Accessed 21 December 2021.

Sirard JR, Pate RR, 2001. Physical activity assessment in children and adolescents. Sports Medicine 31: 439-454. doi: 10.2165/00007256-200131060-00004

Tambalis KD, Panagiotakos DB, Kavouras SA, Kallistratos AA, Moraiti IP, Douvis SJ, Toutouzas PK, Sidossis LS, 2010. Eleven-year prevalence trends of obesity in Greek children: first evidence that prevalence of obesity is leveling off. Obesity (Silver Spring) 18(1):161-6. doi: 10.1038/oby.2009.188

Telama R, Yang X, Laakso L, Viikari J, 1997. Physical activity in childhood and adolescence as predictor of physical activity in young adulthood. American Journal of Preventive Medicine 13(4): 317-323. PMID: 9236971

Trudeau F, Laurencelle L, Tremblay J, Rajic M, Shephard R, 1999. Daily primary school physical education: Effects on physical activity during adult life. Medicine and Science in Sports and Exercise 31(1):111-117. doi: 10.1097/00005768-19990100000018

Tudor-Locke C, Ainsworth BE, Popkin BM, 2001. Active commuting to school: an overlooked source of children's' physical activity? Sports Medicine 31: 309-313.doi: 10.2165/00007256-200131050-00001

US Department of Health and Human Services, US Department of Education 2020. Promoting Better Health for Young People Through Physical Activity and Sports. U.S Department of Health and Human Services. 2008. Guidelines for Physical Activity for Americans. http://www.health.gov/PAGuidelines. Accessed 22 December 2021.

Warren JM, Ekelund U, Besson H, Mezzani A, Geladas N, Vanhees L, 2010. Assessment of physical activity - a review of methodologies with reference to epidemiological research: a report of the exercise physiology section of the European Association of Cardiovascular Prevention and Rehabilitation. European Journal of Cardiovascular Prevention \& Rehabilitation 17: 127-139.doi: 10.1097/HJR.0b013e32832ed875 

be applied to their work. Under the terms of this license, no permission is required from the author(s) or publisher for members of the community to copy, distribute, transmit or adapt the article content, providing a proper, prominent and unambiguous attribution to the authors in a manner that makes clear that the materials are being reused under permission of a Creative Commons License. Views, opinions and conclusions expressed in this research article are views, opinions and conclusions of the author(s). Open Access Publishing Group and European Journal of Physical Education and Sport Science shall not be responsible or answerable for any loss, damage or liability caused in relation to/arising out of conflict of interests, copyright violations and inappropriate or inaccurate use of any kind content related or integrated on the research work. All the published works are meeting the Open Access Publishing requirements and can be freely accessed, shared, modified, distributed and used in educational, commercial and non-commercial purposes under a Creative Commons attribution 4.0 International License (CC BY 4.0). 